\title{
Observational Study Evaluating the Economic Impact of Breakthrough Pain in Cancer Patients in Clinical Practice in Spain: The IMDI Study
}

\author{
Concepción Pérez-Hernández • Antonio Javier Jiménez-López • \\ Almudena Sanz-Yagüe · Javier Mar-Medina · Igor Larrañaga • \\ Begoña Soler-López (D)
}

Received: May 31, 2018 / Published online: July 5, 2018

(c) The Author(s) 2018

\begin{abstract}
Introduction: Breakthrough pain (BTP) has great repercussions on the quality of life, and on the use of health resources. The scope of BTP costs in cancer patients is unknown. The purpose of this study was to evaluate the economic cost of BTP in patients with cancer and the relationship with their quality of life.

Methods: A 1-month observational prospective cost-of-illness study was designed. The patients recorded the consumption of health resources
\end{abstract}

Enhanced digital features To view enhanced digital features for this article go to https://doi.org/10.6084/ m9.figshare.6635465.

C. Pérez-Hernández

Pain Unit, Hospital Universitario de la Princesa,

Madrid, Spain

A. J. Jiménez-López · A. Sanz-Yagüe

Medical Department, Kyowa Kirin Farmacéutica,

S.L.U, Madrid, Spain

J. Mar-Medina

Hospital Alto Deba, Unidad de Gestión Sanitaria,

Mondragón, Spain

I. Larrañaga

Hospital Alto Deba, Unidad de investigación AP-

OSis Gipuzkoa, Mondragón, Spain

B. Soler-López ( $\square)$

Medical Department, E-C-BIO, S.L., Las Rozas

(Madrid), Spain

e-mail: bsoler@ecbio.net and drugs related to BTP in a diary. The current symptoms in Edmonton Symptoms Assessment Scale (ESAS) and their quality of life (EORTC QLQ-C30, version 3) were assessed. The direct medical and non-medical costs fixed and variable and the indirect costs of the patient and the caregivers were evaluated. Factors related to cost and quality of life were identified using linear generalized models (LGM) type gamma and logistic link. Participants were oncologic patients with BTP, older than 18 years, with controlled basal pain.

Results: Eight Spanish pain units, eight palliative care units, and one oncology department included 152 patients. One hundred patients $(65.8 \%)$ were male and the mean age was 66.8 years (95\% CI 64.8-68.8). The total cost per patient was 2941.60 euros per month: 88\% direct medical costs, 5\% non-medical direct costs, and $7 \%$ indirect costs due to lost productivity. A better score in EORTC QLQ-30 quality of life was associated with a reduction in overall costs.

Conclusions: The study showed the results of the first real-life prospective study evaluating the cost of illness of BTP in cancer patients demonstrating that the presence of breakthrough pain in a cancer patient causes a very significant increase in healthcare costs.

Funding: Kyowa Kirin Farmacéutica, S.L.U. 
Keywords: Breakthrough pain; Cancer; Cost of illness; Pharmacoeconomics

\section{INTRODUCTION}

Breakthrough pain (BTP) is defined as a "transient exacerbation of pain that occurs either spontaneously, or in relation to a specific predictable or unpredictable trigger, despite relatively stable and adequately controlled background pain" [1]. It is characterized by reaching the peak of pain within the first $5 \mathrm{~min}$, it is of severe intensity and short duration, usually less than $60 \mathrm{~min}$, and it occurs 3-5 times a day [2-4]. The formal description of BTP was not established until 1990, so it is a very recent nosological term [4]. Recognition of this clinical entity was included in a consensus document between the Spanish Societies of Medical Oncology, Palliative Care and Pain in 2002, and by the Association for Palliative Medicine of Great Britain in 2009 [1, 5].

A prevalence of BTP of up to $66 \%$ has been observed in cancer patients. BTP is more common in patients with low performance status, advanced stages of disease, and when weightbearing bones and nerve plexuses are affected, and it has been confirmed that the occurrence of BTP is associated with poor prognosis $[2,6,7]$.

BTP has a very significant impact on the quality of life of patients, and it is also characterized by being associated with a high use of healthcare resources $[8,9]$.

Because of the large etiological diversity of BTP, its treatment must have a multiple approach with drugs, especially opioids, being an essential part for the success of treatment. Sufficient studies have not been performed describing routine clinical practice in this type of patients, and this limitation prevents adequate evaluation of the added value of new treatments and their impact on costs. However, it is known that up to $77 \%$ of patients are not adequately diagnosed or treated [5].

The lack of knowledge about current costs and the results of treatment of BTP could convey the idea that it is not a priority in currentday medicine. Development of knowledge in this area is therefore essential for correct planning of healthcare systems, especially considering the relevance of cancer in our current society.

To resolve this limitation, more information about real-life clinical practice for the management of patients with BTP, and their results in terms of quality of life and costs are needed.

The aim of this study was to measure the economic impact of breakthrough pain in cancer patients in a prospective follow-up. Both fixed and variable direct medical and nonmedical costs and indirect costs of the patient and caregivers were evaluated, following the economic model of breakthrough pain proposed by Abernethy et al. [10].

\section{METHODS}

\section{Study Design and Ethical Standards}

An observational study with 1 month follow-up of patients was designed. The study visits were adapted to routine clinical practice, scheduling an initial visit and phone contacts or visits on days $1,3,5$, and 7 , and a visit at 1 month from patient selection. Patients were provided with a diary to collect data on consumption of drugs and healthcare resources. The patients were included between April 2015 and March 2016.

The study was approved by the Clinical Research Ethics Committee of Hospital Universitario de La Princesa de Madrid (Spain) with code number 2488. All patients received information about the study and agreed to participate by signing the informed consent form. All procedures performed in the study were in accordance with the ethical standards of the institutional and national research committee and with the 1964 Helsinki Declaration and its later amendments. Informed consent was obtained from all individual participants included in the study.

Patients were included in 17 centers from 16 Spanish provinces. The study was completed in eight pain units, eight palliative care units, and one oncology department. 


\section{Selection Criteria}

Patient screening was performed on a consecutive random basis, selecting the first ten patients visiting the clinic and who met the selection criteria. The information sources were the clinical history and the data collected on each visit.

Patients of any race and gender were included in the study if they were over 18 years of age with a diagnosis of BTP and controlled background pain with oncological baseline disease and ambulatory when selected for the study who agreed to participate. Patients were excluded if they had cognitive impairment, were severely affected by their underlying disease or were uncooperative, or unable to complete unaided or aided the data necessary for the study.

BTP was defined according to the criteria of Portenoy et al. as the presence of persistent background pain lasting 12 or more hours per day during the week before the evaluation or which would exist if treatment were not taken, which is adequately controlled, i.e., there is no or mild pain with a pain intensity score on the visual analogue scale of 4 or less points, and which exhibits transient exacerbations of pain [4].

\section{Sociodemographic and Clinical Variables}

The variables recorded were date of birth, gender, weight, height at the time of the visit, socioeconomic level (low: incomes less than two-thirds of the mean salary, 15,000 euros; middle: incomes between two-thirds and twice the mean salary, $>15,000$ euros and $<45,000$ euros; or high: incomes higher than twice the mean salary, $>45,000$ euros), and performance status of the patient measured by the Karnofsky Performance Status [11]. Information was collected on the patient's clinical history and the type of tumor and date of diagnosis.

Information collected about the main characteristics of BTP are described in Table 1.

\section{Clinical Assessment}

Patients were asked to complete four questionnaires on the baseline visit and at the end of the month of follow-up:

1. Assessment of pain intensity at the time of the visit using a $10-\mathrm{cm}$ visual analogue scale (VAS), where 0 indicated no pain and 10 the maximum pain.

2. The Edmonton Symptoms Assessment Scale (ESAS) was used to evaluate other associated symptoms in the past week (Table 2) [12].

3. Patients completed the Brief Pain Inventory to assess the severity of pain and the impact on patient functionality [13].

4. Quality of life of the patients was measured with the EORTC QLQ-C30 version 3 questionnaire (http://groups.eortc.be/qol/eortcqlq-c30org). Calculation of scores on the questionnaire was done following the instructions and programming of the owners of the questionnaire (Table 3). A higher score represents a higher level of functioning and quality of life on the functional scales $[14,15]$.

At the end of the follow-up period, patients were asked about their satisfaction with treatment of pain on a 10-point visual analogue scale, where 0 meant "not at all satisfied" and 10 "completely satisfied". The patients were satisfied with the treatment if the score was $\geq 5$ points.

\section{Patient Diary}

Patients completed a diary for the 30 days of follow-up in which they recorded the number of visits and hospital admissions, and the consumption of non-healthcare resources and treatments due to or related to breakthrough pain. The doctors confirmed the data recorded by the patients in the diary and transcribed them to the study case report form.

\section{Treatment}

The selected patients received medical treatment and care for their clinical condition and 
Table 1 Characteristics of breakthrough pain by gender

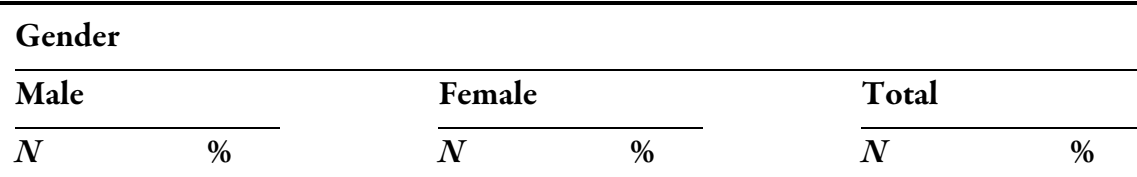

When breakthrough pain started

First episode

Patient under follow-up 56

44

Form of onset

Gradual

Sudden

Intensity

Mild

Moderate

Severe

Unbearable

Is BTP increased by any event?

No, spontaneous

Yes, incidental

45

55

0

26

61

13

52

48

Type of event increasing BTP

Movement
Coughing
Ingestion
Defecation
Other

Total

33

When does BTP predominantly occur?

13

39

25

69

45.4

75

83

54.6

50

71

46.7

26

50

81

53.3

0

10

24

18

0

19.2

0

0

46.2

36

23.7

34.6

85

55.9

31

20.4

69.7

6.1

9.1

9.1

6.1

100

25

27

48.1

51.9

77

75

50.7

49.3

82.6

0

4.3

8.7

4.3

100

23
At night

11

In the daytime

27

Unrelated

62

11

27

62

Indicate how BTP occurs

Unpredictable

69

31

69

31

Predictable

Type of pain

Somatic

12

24.7

11

23

$$
3
$$

16

33

33

32

61.5

101

66.4

38.5

51

33.6

Visceral 
Table 1 continued

\begin{tabular}{|c|c|c|c|c|c|c|}
\hline & \multicolumn{6}{|c|}{ Gender } \\
\hline & \multicolumn{2}{|c|}{ Male } & \multicolumn{2}{|c|}{ Female } & \multicolumn{2}{|c|}{ Total } \\
\hline & $\boldsymbol{N}$ & $\%$ & $N$ & $\%$ & $N$ & $\%$ \\
\hline Neuropathic & 8 & 8.6 & 5 & 10.2 & 13 & 9.2 \\
\hline Mixed & 37 & 39.8 & 21 & 42.9 & 58 & 40.8 \\
\hline Unknown & 1 & 1.1 & 0 & 0 & 1 & 0.7 \\
\hline
\end{tabular}

Table 2 Baseline score of symptoms assessed by the ESAS

\begin{tabular}{|c|c|c|c|c|c|}
\hline & Gender & $N$ & Mean & Standard deviation & $p$ \\
\hline \multirow[t]{2}{*}{ Pain } & M & 98 & 6.4 & 2.4 & \\
\hline & $\mathrm{F}$ & 49 & 6.6 & 2.8 & \\
\hline \multirow[t]{2}{*}{ Tiredness } & $\mathrm{M}$ & 98 & 4.5 & 2.6 & $<0.0001$ \\
\hline & $\mathrm{F}$ & 49 & 6.6 & 2.6 & \\
\hline \multirow[t]{2}{*}{ Nausea } & $\mathrm{M}$ & 97 & 1.6 & 2.1 & $<0.0001$ \\
\hline & $\mathrm{F}$ & 49 & 3.2 & 3.4 & \\
\hline \multirow[t]{2}{*}{ Depression } & $\mathrm{M}$ & 98 & 2.7 & 2.8 & $<0.0001$ \\
\hline & $\mathrm{F}$ & 49 & 4.7 & 3.5 & \\
\hline \multirow[t]{2}{*}{ Anxiety } & $\mathrm{M}$ & 98 & 2.6 & 2.8 & $<0.0001$ \\
\hline & $\mathrm{F}$ & 49 & 5 & 3.4 & \\
\hline \multirow[t]{2}{*}{ Drowsiness } & $\mathrm{M}$ & 98 & 2.7 & 2.6 & 0.003 \\
\hline & $\mathrm{F}$ & 49 & 4.1 & 2.5 & \\
\hline \multirow[t]{2}{*}{ Appetite } & $\mathrm{M}$ & 98 & 4.2 & 2.8 & 0.018 \\
\hline & $\mathrm{F}$ & 49 & 5.4 & 3.3 & \\
\hline \multirow[t]{2}{*}{ Well-being } & M & 98 & 5.6 & 2 & \\
\hline & $\mathrm{F}$ & 49 & 6 & 2.7 & \\
\hline \multirow[t]{2}{*}{ Dyspnea } & $\mathrm{M}$ & 98 & 1.6 & 2.3 & \\
\hline & $\mathrm{F}$ & 49 & 1.8 & 2.4 & \\
\hline \multirow[t]{2}{*}{ Difficulty sleeping } & $\mathrm{M}$ & 98 & 3.8 & 3 & \\
\hline & $\mathrm{F}$ & 49 & 4.4 & 3.1 & \\
\hline
\end{tabular}

$M$ male, $F$ female 
Table 3 Baseline results of EORTC-QLQ-C30 version 3 questionnaire by gender and reference values for age group of 60-69 years and all types of cancer

\begin{tabular}{|c|c|c|c|c|c|c|}
\hline & Gender & $N$ & Mean & Standard deviation & $p$ & $\begin{array}{l}\text { Reference values. } \\
\text { All cancer patients. } \\
\text { Age 60-69 [22] } \\
\text { Mean (SD) }\end{array}$ \\
\hline \multicolumn{7}{|l|}{ Functional scales } \\
\hline \multirow[t]{2}{*}{ Global health status/QoL } & M & 98 & 34.2 & 20.4 & & $61.8(24.4)$ \\
\hline & $\mathrm{F}$ & 49 & 35.2 & 25.1 & & \\
\hline \multirow[t]{2}{*}{ Physical function } & M & 98 & 50 & 26.5 & 0.021 & $76.3(23.5)$ \\
\hline & $\mathrm{F}$ & 49 & 39 & 28.2 & & \\
\hline \multirow[t]{2}{*}{ Role function } & M & 98 & 34.4 & 30.1 & & $72.6(32.7)$ \\
\hline & $\mathrm{F}$ & 49 & 26.9 & 27.6 & & \\
\hline \multirow[t]{2}{*}{ Emotional function } & M & 98 & 61.5 & 25.8 & 0.026 & $71.8(24.3)$ \\
\hline & $\mathrm{F}$ & 49 & 51.7 & 23.3 & & \\
\hline \multirow[t]{2}{*}{ Cognitive function } & M & 98 & 67.7 & 27.3 & & $83.1(21.6)$ \\
\hline & $\mathrm{F}$ & 49 & 61.9 & 24.3 & & \\
\hline \multirow[t]{2}{*}{ Social function } & M & 98 & 43 & 32.4 & & $76.4(28.8)$ \\
\hline & $\mathrm{F}$ & 49 & 35.7 & 31.7 & & \\
\hline \multicolumn{7}{|l|}{ Symptom scales/items } \\
\hline \multirow[t]{2}{*}{ Fatigue } & M & 98 & 51.4 & 24.1 & 0.003 & $34.1(28.2)$ \\
\hline & $\mathrm{F}$ & 49 & 63.7 & 22.9 & & \\
\hline \multirow[t]{2}{*}{ Nausea and vomiting } & M & 98 & 13.4 & 21 & 0.008 & $8.7(19)$ \\
\hline & $\mathrm{F}$ & 49 & 27.2 & 32.2 & & \\
\hline \multirow[t]{2}{*}{ Pain } & M & 98 & 69.6 & 23.3 & & $26.4(30.2)$ \\
\hline & $\mathrm{F}$ & 49 & 75.2 & 23.6 & & \\
\hline \multirow[t]{2}{*}{ Dyspnea } & M & 98 & 21.1 & 32.3 & & $22.1(29.1)$ \\
\hline & $\mathrm{F}$ & 49 & 20.4 & 27.9 & & \\
\hline \multirow[t]{2}{*}{ Insomnia } & M & 98 & 43.5 & 33 & & $28.6(32)$ \\
\hline & $\mathrm{F}$ & 49 & 48.3 & 34.1 & & \\
\hline \multirow[t]{2}{*}{ Appetite loss } & M & 98 & 38.8 & 30.2 & & $21(31.9)$ \\
\hline & $\mathrm{F}$ & 49 & 46.3 & 33.9 & & \\
\hline \multirow[t]{2}{*}{ Constipation } & M & 98 & 31.3 & 31.3 & 0.029 & $17.7(28.8)$ \\
\hline & $\mathrm{F}$ & 49 & 43.5 & 32.8 & & \\
\hline \multirow[t]{2}{*}{ Diarrhea } & M & 98 & 7.1 & 18.7 & & $9.2(20.7)$ \\
\hline & $\mathrm{F}$ & 49 & 5.4 & 17.1 & & \\
\hline
\end{tabular}


Table 3 continued

\begin{tabular}{|c|c|c|c|c|c|c|}
\hline & Gender & $N$ & Mean & Standard deviation & $p$ & $\begin{array}{l}\text { Reference values. } \\
\text { All cancer patients. } \\
\text { Age } 60-69 \\
{[22] \text { Mean (SD) }}\end{array}$ \\
\hline \multirow[t]{2}{*}{ Financial difficulties } & $\mathrm{M}$ & 95 & 28.4 & 323 & & $13.8(26.4)$ \\
\hline & $\mathrm{F}$ & 48 & 37.5 & 37.4 & & \\
\hline
\end{tabular}

$M$ male, $F$ female

for BTP according to the specialist's clinical judgment.

\section{Recording of BTP Costs}

The cost study was performed by measuring direct medical costs (hospital and drug costs), direct nonmedical costs, and indirect costs (Table 4). Medical costs were associated with resource consumption and were calculated by multiplying the number of resources used by unit cost. Unit costs of healthcare resources, diagnostic tests and treatments were obtained by taking the average value of the prices obtained in the official bulletins of public prices and tariffs of the Autonomous Communities of Andalusia, Castile and Leon, Catalonia, Galicia, Madrid and Basque Country, and the Oblikue health care cost database [16].

Information was collected on the treatments administered for BTP, their trade names, doses, and daily dosing frequency and the duration of the treatments, to calculate the total number of doses per patient. Unit costs of the treatments were obtained from the BOTPLUS 2.0 database [17].

Direct nonmedical costs included non-protocolized care or time used by relatives or caregivers to care for the patient in the hospital or their home. Non-protocolized care was defined as unpaid care provided by non-professional persons to help patients with limitations in their autonomy in their daily activities. The cost substitution method based on the average salary was used. The approach used to assess care hours was the proxy method, which calculates time as a result. This method assigns the sum of the care performed by the non-professional caregiver (13.14€ per hour), considering that if he/she had not provided these services, his/her functions would have been performed by a professional caregiver [18, 19].

Indirect costs were defined as the value of the loss of productivity derived from breakthrough pain in the patient and the cost derived from impact on the patient's caregivers. The caregiver is the person from the patient's family or immediate surroundings who dedicates part of their time to care for the patient. Their cost was measured in terms of loss of work productivity if work leave is received and by the time dedicated. The cost of each day of work leave was obtained from the Quarterly Labour Cost Survey. The per hour of informal caregiver care was also obtained from this survey in section o) other social activities and services provided to the community; personal services [20].

\section{Statistical Analysis}

A descriptive analysis was completed of the variables included in the study using standard descriptive statistics. Comparisons between qualitative variables were made using Fisher's test or Chi-square test. Student's $t$ test was used to compare independent groups in the case of quantitative variables. The statistical significance level was set as 0.05. SPSS version 23.0 statistical package was used for the analysis.

The results of the cost study were presented as cost per patient and broken down by different components. Because the costs did not follow a normal distribution, nonparametric tests were applied to compare costs between different 
Table 4 Monthly cost per patient by type of resource consumed

\begin{tabular}{|c|c|c|c|}
\hline Resource & $\begin{array}{l}\text { Contacts per patient mean } \\
\text { (standard deviation) }\end{array}$ & $\begin{array}{l}\text { Unit cost } \\
\text { in euros }\end{array}$ & $\begin{array}{l}\text { Monthly cost per } \\
\text { patient in euros }\end{array}$ \\
\hline Direct medical costs & & & $2572.5 €$ \\
\hline Cost of visits and admissions & & & $1879.9 €$ \\
\hline Visit to primary care physician & $0.45(1)$ & $55.2 €$ & $23.2 €$ \\
\hline Visit to specialist physician & $3.99(4.72)$ & $168.3 €$ & $477.1 €$ \\
\hline Visit to emergency unit & $0.31(0.75)$ & $188.6 €$ & $58.8 €$ \\
\hline Visit to day hospital & $0.36(1.07)$ & $176.5 €$ & $64.1 €$ \\
\hline Visit by home hospitalization unit & $1.07(3.17)$ & $168.2 €$ & $179.9 €$ \\
\hline Hospital admission & $2.05(4.56)$ & $509.6 €$ & $1.045 .9 €$ \\
\hline Radiotherapy session & $0.69(2.46)$ & $44.8 €$ & $31.0 €$ \\
\hline Cost of imaging tests & & & $153.1 €$ \\
\hline Cost of laboratory tests & & & $39.1 €$ \\
\hline Cost of treatments (pharmacy) & & By product & $500.3 €$ \\
\hline Nonmedical direct costs & & & $168.5 €$ \\
\hline Cost of nonhealthcare resources & & & $48.8 €$ \\
\hline Psychotherapy session & $0.49(1.57)$ & $57.2 €$ & $19.9 €$ \\
\hline Physiotherapy session & $1.07(3.83)$ & $27.0 €$ & $28.8 €$ \\
\hline Cost of caregiver & & & $119.7 €$ \\
\hline Paid caregiver & & & $8.9 €$ \\
\hline Unpaid caregiver & & & $110.8 €$ \\
\hline Indirect costs due to loss of productivity & & & $200.7 €$ \\
\hline Cost of patient leave & & & $188.1 €$ \\
\hline Cost of caregiver leave & & & $12.5 €$ \\
\hline Total cost & & & $2.941 .6 €$ \\
\hline
\end{tabular}

factors. The Mann-Whitney $U$ test was used to compare variables between two groups and the Kruskal-Wallis test to compare variables with more than two groups. In the analysis of resource utilization, rates adjusted to 30 days of follow-up were calculated per patient. As a final point, a multivariate analysis was performed to identify factors related to cost and quality of life, and baseline characteristics of the patients that could be associated independently with an increase or decrease in these factors. For this purpose, generalized linear models (GLM) were used, a generalization of least-squares linear regression that allows the response variable to follow non-normal distributions [21]. The GLM family was selected by the AIC statistic using the $\mathrm{R}$ statistical package. Thus, multivariate analyses were carried out with GLM in which total cost was included as the dependent variable, using sociodemographic and clinical information (gender, age, initial QoL, QoL increase, main drug, type of onset of BTP) as co- 
variables. The values of the dependent variable, total cost, were log-transformed to adjust them to the models.

Sample size was calculated based on one study on patients with breast cancer where the monthly costs on the metastatic cancer was 1489 euros. For a standard deviation of 250 euros and a 95\% confidence interval and a precision of 41.68 euros, it was estimated that a sample of 140 patients yield a power of $80 \%$ [22].

\section{RESULTS}

A total of 152 patients were included in the study, of which 140 proved valid for the economic analysis. Each center included an average of nine patients (95\% CI 7-11). Mean follow-up was 28.9 days (CI 95\% 27.9-30), with a median of 30 days, a minimum of 1 and maximum of 47 days. A total of 137 patients (90.1\%) completed the 30 days of study follow-up. Follow-up was interrupted by medical decision in two cases $(1.3 \%)$, and in two more cases the patient decided not to continue in the study $(1.3 \%)$. Four patients $(2.6 \%)$ were lost to follow-up and six patients died during the study (3.9\%).

\section{Sociodemographic Data and Medical History}

One hundred patients (65.8\%) were men and 52 were women $(34.3 \%)$, with a mean age of 66.8 years (95\% CI 64.8-68.8), with no differences between genders (0.39). The socioeconomic level was middle in 106 (71.6\%), followed by low in 27 (18.2\%), and high in 15 (10.1\%) patients, respectively.

There were no significant differences in body mass index (BMI) between men and women, which was $24.6 \mathrm{~kg} / \mathrm{m}^{2}$ (95\% CI 23.9-25.2), with a median of $24.3 \mathrm{~kg} / \mathrm{m}^{2}$.

The tumor was in the gastrointestinal tract in 35 patients (23\%), lung in $34(22.4 \%)$, breast in $14(9.2 \%)$, prostate gland in $8(5.3 \%)$, and in other body locations in 61 cases $(40.1 \%)$. At study entry, $63.8 \%$ of cancer patients (97 patients) had metastases.
The time from diagnosis of the tumor to the study visit was 2.4 years (95\% CI 1.9-3), with a median of 1.2 years. This information could not be calculated in 18 patients as tumor diagnosis date was not available (11.8\%).

The proportion of patients corresponding to each Karnofsky score was: 20, el $0.7 \%$ (1); 30, el $1.3 \%$ (2); 40, 6.6\% (10); 50, 18.4\% (28); 60, $21.1 \%$ (32); 70, 21.7\% (33); 80, 20.4\% (31); 90, $9.2 \%(14)$; and 100, 0.7\% (1).

\section{Characteristics and Symptoms of BTP}

A total of 69 patients (45.4\%) presented their first BTP episode when they were included in the study. A higher proportion of male patients included in their first episode of BTP was observed $(p<0.0001)$. The mean number of episodes of BTP per day was 3.1 (95\% CI 2.8$3.4)$, with a median of three episodes. The mean duration of BTP was $30.6 \mathrm{~min} \quad(95 \%$ CI 24.8-36.4), with a median of $20 \mathrm{~min}$. Table 1 summarizes the characteristics of BTP by gender. Significant differences were only observed in the proportion of patients with unbearable pain, which was larger in women $(p=0.007)$.

Pain intensity assessed by the VAS at the time of the visit was 4.67 points (95\% CI 4.24-5.1), with a median of 5 points, and no differences between genders $(p=0.895)$. Table 2 shows the mean ESAS scores and the differences found between genders.

\section{Brief Pain Inventory}

The mean score on the pain intensity dimension of the Brief Pain Inventory was 4.9 points (95\% CI $4.7-5.1$ ), with a median of 4.8 , minimum of 1.5 , and maximum of 9.8 . The mean score on the impact on daily living activities dimension of the Brief Pain Inventory was 6.1 points (95\% CI 5.8-6.5), with a median of 6.3 , minimum of 0 , and maximum of 10 .

\section{EORTC QLQ-C30 Version 3 Questionnaire}

Tables 3 lists the scores on the five functional and symptom scales of the quality of life questionnaire by gender, as well as the reference 
Table 5 Multivariate analysis with total cost as result variable

\begin{tabular}{lllll}
\hline Generalized linear model & Adjusted OR & Lower CI & Upper CI & $\boldsymbol{p ~ v a l u e ~}^{\mathbf{a}}$ \\
\hline Gender: male versus female & 0.963 & 0.639 & 1.430 & 0.852 \\
Age: $<66.5$ years versus $\geq 66.5$ years & 0.931 & 0.652 & 1.328 & 0.692 \\
Initial QoL & 0.981 & 0.972 & 0.991 & 0.000 \\
Quality of life increase ( $\Delta$ QoL) & 0.991 & 0.983 & 0.999 & 0.027 \\
Onset of breakthrough pain: First diagnosis versus in follow-up & 0.816 & 0.554 & 1.202 & 0.294 \\
\hline OR odds ratio, $C I$ confidence interval, $\triangle Q 0 L$ continuous variable collecting the difference in QoL between baseline and final \\
questionnaires \\
${ }^{2}$ Calculated using generalized linear models (Family: Gamma, Link: Log)
\end{tabular}

values for patients with any type of cancer and ages from 60 to 69 years [23].

\section{Patient Satisfaction}

One hundred and nineteen patients (88.1\%) were satisfied with the pain treatment they were receiving, with a mean score of 7.7 points $(95 \%$ CI 7.4-8.1), and median score of 8 points. This information was not recorded in 17 patients $(11.2 \%)$ due to withdrawal or death (14 patients) and three did not complete the VAS.

\section{Analysis of Breakthrough Pain Costs}

Although information was collected from 152 patients in the study, the total number of patients used to perform the economic analysis was 140 , since 12 cases were excluded: In four cases, the patients were hospitalized during the follow-up period and in the other eight patients no data were collected about resource utilization.

The descriptive analysis of resource consumption is presented in Table 4 . It is presented as the cost adjusted to 30 days of follow-up and broken down into different components. A total cost per patient of 2941.60 euros was observed, with 2572.50 euros for direct medical costs, which accounted for $88 \%$ of the cost per patient, 168.50 euros for direct nonmedical costs (5\%), and 200.70 euros for indirect costs due to loss of productivity (7\%).

In the GLM analysis of the total cost per patient adjusted by the co-variables, no significant differences were observed in demographic factors (age, gender). However, it was observed that the better the overall score on quality of life, the lower was the cost of treatment of BTP in the patient (Table 5).

\section{DISCUSSION}

The results of the study show that the cost of breakthrough pain in cancer patients is very high, reaching 2.941,60 euros/month, and with an annual cost per patient of 35,299.20 euros, assuming the distribution of annual costs is proportional. Direct medical costs account for $88 \%$ of the cost of BTP, direct nonmedical costs for $5 \%$, and indirect costs due to loss of productivity for $7 \%$.

In our study, it was observed that drug costs of BTP represented $17 \%$ of the total costs, and $19 \%$ of direct medical costs. The weight of hospital admissions in the management of patients with BTP, which is determined by baseline disease, is especially notable, though it was not possible to differentiate if admission was due to breakthrough pain. It was also observed that patient work leaves had little weight on costs, since patients could be in a situation of disability leave or retirement. It has been shown that improved symptom control not only improves quality of life but also reduces overall cost, thus justifying treatment and its cost $[23,24]$. In our study, it was observed that for each 10 points of improvement in initial quality of life the odds ratio was 0.83 , which meant that the cost was $17 \%$ less. It was also 
observed that for each 10 points of improvement in quality of life during the month of follow-up, the odds ratio was 0.91 , and therefore the reduction in cost was $9 \%$ (Table 5). Few pharmacoeconomic studies have been conducted on the cost of BTP $[10,25,26]$. We did not find any study in the current literature evaluating the costs prospectively in real patients and considering direct and indirect costs of treatment of BTP, with which to compare the results of our study.

The study of Taylor et al. was conducted in non-cancer patients and only assessed the impact of BTP on quality of life [27]. In the study published by Fortner in 2003, it was observed in a sample of 373 patients that 23\% (33) had BTP, that patients with BTP had higher monthly direct costs related to pain $(\$ 1080)$ compared to patients without BTP (\$750), and that indirect costs were also higher ( $\$ 88$ vs. $\$ 53$ ) [8].

The study by Fortner et al. in 2002 collected information from a sample of 160 cancer patients who were receiving standard care for control of chronic pain and who had BTP, and 89 cancer patients without BTP. It was a telephone survey performed directly to the patients, in which patients were asked about their consumption of resources and treatments during the previous year. The estimated cost per patient in this study was $\$ 12,000 /$ year in patients with BTP and $\$ 2.400 /$ years in patients without BTP, i.e., the annual cost was five times higher in cancer patients with BTP. This supports the idea that the presence of BTP in a cancer patient leads to a very significant increase in their healthcare costs. Comparing to the data from our study, resource consumption was nearly three times higher than that recorded in the study of Fortner. The proportion of the cost corresponding to hospital admissions was $81 \%$ of total costs; however, in our study it represented $35.5 \%$ of total costs [9].

The results on the intensity of symptoms evaluated by the ESAS (Table 2) showed acceptable mean scores, the majority below 5 points, which means adequate control of the symptoms presented by cancer patients.
In the comparison of the results of the EORTC QLQ-C30 questionnaire in the study patients with reference values for cancer patients of the same age and with any type of cancer from a sample of 6709 patients, worse overall quality of life was found on all the functional scales and greater intensity on all the symptoms scales (Table 3) in the study patients. This greater impairment may or may not be attributable to the presence of breakthrough pain since no information is available from a control group without breakthrough pain.

One limitation in the interpretation of the data of this study was that the patients included in the study had different types of tumors and different stages of the disease and time of follow-up, which might have influenced both their quality of life and costs. Patients may have overestimated their consumption of resources and part of them may be attributed to their underlying cancer. Although the data were verified by the doctors so that the costs recorded were only attributable to BTP, in many cases the costs due to underlying disease or BTP could not be properly differentiated. Collection of data for only a month also limits extrapolation of the data to an annual period, but this design gave more viability to the project. Intangible costs produced by BTP were not assessed, although it is an assessment omitted in most pharmacoeconomic studies due to the difficulty of their measurement.

\section{CONCLUSIONS}

In this study, we evaluated the cost of the disease prospectively and using real-life data in a study designed specifically to perform this assessment. Future studies will be needed to evaluate the cost-effectiveness of the treatments for BTP and studies measuring the costs of the disease directly in non-cancer patients with BTP, to be able to deduce the cost attributable to BTP as an independent clinical entity. Our study reaffirms the need to adopt a proactive approach in the care of these patients since their quality of life can be improved, and it results in a reduction in the cost of their care. 


\section{ACKNOWLEDGEMENTS}

We wish to thank the ethics committees of the centers participating in the study for their collaboration. We also thank the participation of the following investigators in the IMDI study: Pilar Anadon Senac, Alvaro Deblas Sandoval, Adela Delgado Alvarez de Sotomayor, Ernesto Delgado Cidranes, Diego Díaz Cárdenas, Diego Díaz Rodríguez, Silvia Forcano Sanjuan, María López Gómez, Mercedes López Luque, Raquel Marsé Fabregat, Marcelino Mosquera Pena, Mercedes Mozas Calabaza, Ferran Nonell i Gregori, Miguel Ángel Núñez Viejo, Manuel Ojeda Martín, Rogelio Sánchez de las Matas Peña.

Funding. Concepción Pérez-Hernández received funding from Kyowa Kirin Farmacéutica, S.L.U. as an Investigator Sponsored Study, for the completion of the study and article processing charges. All authors had full access to all the data in this study and take complete responsibility for the integrity of the data and accuracy of the data analysis.

Authorship. All named authors meet the International Committee of Medical Journal Editors (ICMJE) criteria for authorship for this article, take responsibility for the integrity of the work, and have given their approval for this version to be published.

Prior Presentation. The results of the study were presented as a poster communication at XIV Congress of the Spanish Society of Pain (Sociedad Española del Dolor, SED), June 1-3 June, 2017.

Disclosures. Concepción Pérez-Hernández received funding from Kyowa Kirin Farmacéutica, S.L.U. as an Investigator Sponsored Study, for the completion of the study. She was the Sponsor of the study and participates in the design, inclusion of patients, review of statistical report and publications. Antonio Javier Jiménez-López belongs to the Medical Department of Kyowa Kirin Farmacéutica, S.L.U. Almudena Sanz-Yagüe belongs to the Medical
Department of Kyowa Kirin Farmacéutica, S.L.U. Javier Mar-Medina was contracted by Concepción Pérez-Hernández and Kyowa Kirin Farmacéutica, S.L.U. for designing of the study, monitoring, statistical analysis and management of the study publications. Igor Larrañaga was contracted by Concepción Pérez-Hernández and Kyowa Kirin Farmacéutica, S.L.U. for designing of the study, monitoring, statistical analysis and management of the study publications. Begoña Soler-López was contracted by Concepción Pérez-Hernández and Kyowa Kirin Farmacéutica, S.L.U. for designing of the study, monitoring, statistical analysis and management of the study publications.

Compliance with Ethics Guidelines. The study was approved by the Clinical Research Ethics Committee of Hospital Universitario de La Princesa de Madrid (Spain) with code number 2488. All patients received information about the study and agreed to participate by signing the informed consent form. All procedures performed in the study were in accordance with the ethical standards of the institutional and national research committee and with the 1964 Helsinki Declaration and its later amendments. Informed consent was obtained from all individual participants included in the study.

Data Availability. The datasets generated during and/or analyzed during the current study are available from the corresponding author on reasonable request.

Open Access. This article is distributed under the terms of the Creative Commons Attribution-NonCommercial 4.0 International License (http://creativecommons.org/licenses/ by-nc/4.0/), which permits any noncommercial use, distribution, and reproduction in any medium, provided you give appropriate credit to the original author(s) and the source, provide a link to the Creative Commons license, and indicate if changes were made. 


\section{REFERENCES}

1. Davies AN, Dickman A, Reid C, Stevens AM, Zeppetella G, Science Committee of the Association for Palliative Medicine of Great Britain and Ireland. The management of cancer-related breakthrough pain: recommendations of a task group of the Science Committee of the Association for Palliative Medicine of Great Britain and Ireland. Eur J Pain. 2009;13(4):331-8.

2. Gómez-Batiste X, Madrid F, Moreno F, et al. Breakthrough cancer pain: prevalence and characteristics in patients in Catalonia, Spain. J Pain Sympt Manage. 2002;24(1):45-52.

3. Porta-sales J, Garzón C, Juliá J, Casals Merchán M. Dolor irruptivo en cáncer. Med Clin. 2010;135(6):280-5.

4. Portenoy RK, Hagen NA. Breakthrough pain: definition, prevalence and characteristics. Pain. 1990;41(3):273-81.

5. Escobar Álvarez Y, Biete i Solà A, Camba Rodríguez $\mathrm{M}$ et al. Diagnóstico y tratamiento del dolor irruptivo oncológico: Recomendaciones de consenso. Med Paliat. 2013;20(4):150-7.

6. Deandrea S, Corli O, Consonni D, et al. Prevalence of breakthrough cancer pain: a systematic review and a pooled analysis of published literature. J Pain Symptom Manage. 2014;47(1):57-76.

7. Nekolaichuck CL, Fainsinger RL, Lawlor PG. A validation study of a pain classification system for advanced cancer patients using content experts: the Edmonton Classification System for Cancer Pain. Palliat Med. 2005;19(6):466-76.

8. Fortner BV, Demarco G, Irving G, et al. Description and predictors of direct and indirect costs of pain reported by cancer patients. J Pain Symptom Manage. 2003;25(1):9-18.

9. Fortner BV, Okon TA, Portenoy RK. A survey of pain-related hospitalizations, emergency department visits, and physician office visits reported by cancer patients with and without history of breakthrough pain. J Pain. 2002;3(1):38-44.

10. Abernethy AP, Wheeler JL, Fortner BV. A health economic model of breakthrough pain. Am J Manag Care. 2008;14:S129-40.

11. Schag CC, Heinrich RL, Ganz PA. Karnofsky performance status revisited: reliability, validity, and guidelines. J Clin Oncol. 1984;2(3):187-93.

12. Bruera E, Kuehn N, Miller MJ, Selmser P, Macmillan K. The Edmonton Symptom Assessment System
(ESAS): a simple method for the assessment of palliative care patients. J Palliat Care. 1991;7(2):6-9.

13. Badia X, Muriel C, Gracia A, et al. Validation of the Spanish version of the brief Pain Inventory in patients with oncological pain. Med Clin (Barc). 2003;120(2):52-9.

14. Aaronson NK, Ahmedzai S, Bergman B, et al. The European Organization for Research and Treatment of Cancer QLQ-C30: a quality-of-life instrument for use in international clinical trials in oncology. J Natl Cancer Inst. 1993;85(5):365-76.

15. Fayers PM, Aaronson NK, Bjordal K, et al., on behalf of the EORTC Quality of Life Group. The EORTC QLQ-C30 scoring manual, 3rd edition. European Organisation for Research and Treatment of Cancer, Brussels 2001.

16. Spanish Cost Database, e-salud. Oblikue consulting: http://www.oblikue.com/bddcostes/. Accessed 10 Nov 2017.

17. BotPlus 2.0. Consejo General de Colegios Oficiales de Farmacéuticos. https://botplusweb.portalfarma. com/. Accessed 10 Nov 2017.

18. Informe del IMSERSO. Las personas mayores en España. Informe 2008. http://www.imserso.es/ InterPresent2/groups/imserso/documents/ binario/ infppmm2008vol1.pdf. Accessed 10 Nov 2017.

19. Van den Berg B, Brouwer WBF, Koopmanschap MA. Economic valuation of informal care. An overview of methods and applications. Eur J Health Econ. 2004;5(1):36-45.

20. Encuesta trimestral del coste laboral. Instituto Nacional de Estadística. http://www.ine.es/daco/ daco42/etcl/etcl0316.pdf. Accessed 10 Nov 2017.

21. Glick HA, Doshi JA, Sonnad SS, et al. Economic evaluation in clinical trials. Oxford: Oxford University Press; 2014.

22. Arrospide A, Soto-Gordoa M, Acaiturri T, López-Vivanco G, Abecia LC, Mar J. Coste del tratamiento del cáncer de mama por estadio clínico en el País Vasco. Rev Esp Salud Pública. 2015;89(1):93-7.

23. Scott NW, Fayers PM, Aarouson NK et al. EORTC QLQ-C30 Reference Values, 2008. http:/groups. eortc.be/qol/manuals. Accessed 29 June 2018.

24. Fortner BV, Okon TA, Ashley J, et al. The Zero Acceptance of Pain (ZAP) Quality Improvement Project: evaluation of pain severity, pain interference, global quality of life, and pain-related costs. J Pain Symptom Manage. 2003;25(4):334-43. 
25. Kuo KL, Saokaew S, Stenehjem DD. The pharmacoeconomics of breakthrough cancer pain. J Pain Palliat Care Pharmacother. 2013;27(2):167-75.

26. Velucci R, Mediati RD, Gasperoni S, et al. Pharmacoeconomic considerations about breakthrough cancer pain. Value Health. 2015;18(7):A665-6. https://doi.org/10.1016/j.jval.2015.09.2426.
27. Taylor DR, Webster LR, Chun SY, et al. Impact of breakthrough pain on quality of life in patients with chronic, noncancer pain: patient perceptions and effect of treatment with oral transmucosal fentanyl citrate (OTFC, ACTIQ). Pain Med. 2007;8(3):281-8. 